\title{
Inclusiveness and Empowerment in Old Community Renovation Design
}

\author{
Jinbai WANG, Tongji Urban Planning \& Design Institute Co., Ltd., China
}

\begin{abstract}
This article seeks to provide a reproducible project experience for the inclusive transformation of old communities. Not only through questionnaire surveys, panel interviews, demand cards, scene simulations, etc., the daily behavior and activity space of the dominant crowd in the area's current space is summarized, and "three pictures and one table" are drawn: current crowd space behavior analysis diagram, crowd space facility demand notes Recording diagrams, simulation diagrams of current residents' life scenes, and residents' demand statistical information tables. In addition, the population description and demand simulation are carried out, and the ten major life pain points of community life are summarized, and the optimization strategies for the ten major life scenarios are proposed. In the community, four types of facilities, including centralized facilities, pocket convenience points, smart interaction points, and characteristic quality points, are arranged, and two types of life scenarios are created for basic services and quality improvement. This design method can more three-dimensionally interpret the living conditions of residents in the community, accurately grasp the pain points in life, and carry out more targeted transformation design, which reflects the characteristics of community empowerment and inclusive design.
\end{abstract}

\section{Keywords}

Inclusiveness, Empowerment, Old Community, Life Scene

\section{Introduction}

China's old communities are mostly non-commercial housing built by the government and state-owned enterprises for their employees. The portraits of the original residents in the communities are similar, the community functions are single, and the supporting facilities are incomplete, which can hardly meet the living needs of today's all-aged community residents. The Xinhua News Agency said, "Old streets, old yards, old houses, old facilities, and poor living environment are the common dilemmas of "four olds and one poor" in old communities. They have not only become a "big worry" for residents of the community, but also a major issue in the governance of modern cities and communities." (Zhu et al., 2019). The reconstruction of the old community will improve the quality of life of residents and stimulate potential consuming capability in the community.

The General Office of the State Council of China issued the "Guiding Opinions of the General Office of the State Council on Comprehensively Promoting the Reconstruction of Old Communities in Urban Areas" in 2020 (PRC, 2020). The rebuilding of the old community is included in the work schedule of governments at all levels, which means that the transformation of old housing estates has become China's strategic goal. The majority feature of old community renovation design is recognizing the needs and requirements of the people who live in the community. The information from the community residents is the key to do the community renovation design. Inclusive design and empowerment of ther community have the 
capability to deal with the issue. This article aims to do the research on renovating old communities and solve the problem of single function and inadequate supporting facilities for old communities through inclusive design and community empowerment in China and provide experience and a reference for China's renovation and renewal projects.

This paper will firstly review and summary the literature in this field. Then, the majority process of "Three Diagrams and One Table" of the method will be introduced to the audience. Third, the research analysis and outcomes of "Three Diagrams and One Table" will be the core part of this paper. Fourth, this article will take the advantage of the research results to do the renovation design in the real world. Last but not the least, this article will conclude the research and talk about the future investigation.

\section{Literature Review}

\subsection{Inclusive design and empowerment in the global area}

Using Dimensions, the world's largest linked research information dataset, search the keywords "inclusive design" and "empowerment of community" in English and Chinese. The results show that the number of Chinese articles is 1,564 and the English articles are 203,293. Figure 1 and Figure 2 each show the number of Chinese articles and the number of English papers. The number tells us that Chinese scholars have relatively little literature and research on inclusive design and community empowerment compared to International scholars. This article will contribute to the research of inclusive design and empowerment of community with Chinese characteristics. Kusumaningdyah and Ratri take the case study of Kampung Kota Surakarta in Japan as an example to evaluate human-centered design methods as an approach for inclusive green design $(H$ and $W, 2021)$. Hübscher and Ringel criticized Santa Cruz Verde 2030 for not adopting sufficient public participation procedures, "The analysis shows that the interviewees feel insufficiently informed by the project's initiators. The project is interpreted as an elitist symbol of how the project's initiators understand urban development." (Hübscher and Ringel, 2021). De Weger et al., argues that community engagement is increasingly seen as crucial to achieving high quality, efficient and collaborative care (De Weger et al., 2018). This article will contribute to the research of inclusive design and empowerment of community with Chinese characteristics.

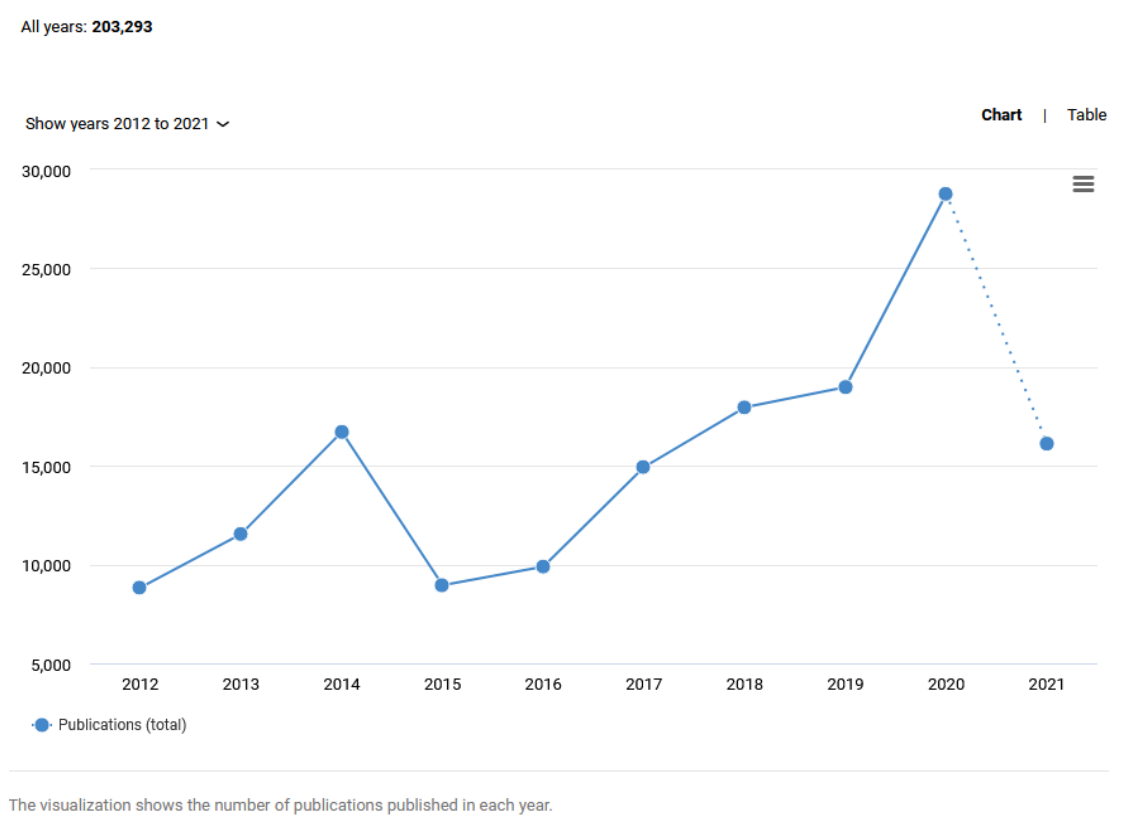

Figure 1. The number of publications of English articles published in each year.

Source: https://app.dimensions.ai/discover/publication 


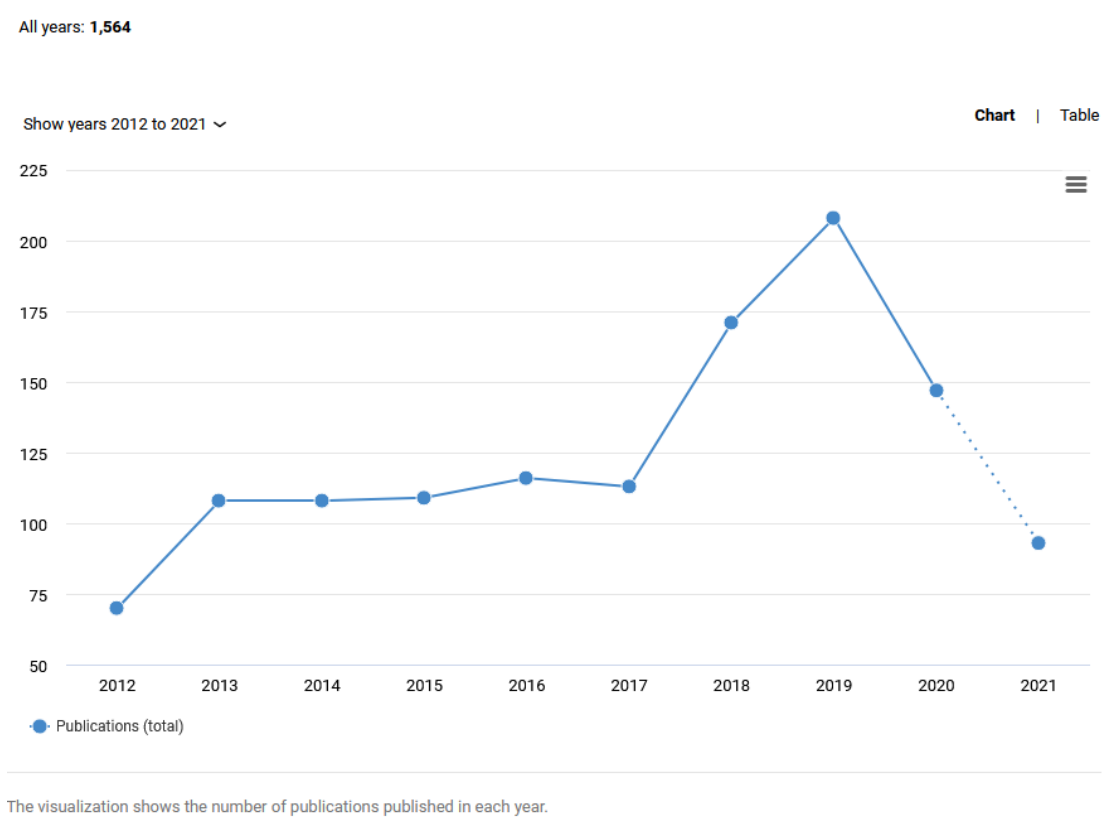

Figure 2. The number of publications of Chinese articles published in each year.

Source: https://app.dimensions.ai/discover/publication

\subsection{Inclusive design and empowerment in newly-developed projects or existing issues}

Adding "renovation" as an extra keyword, the results show that the number of publications of renovation-related articles in English and Chinese published is 26,312 (Figure 3 and Figure 4). It's much lower than the number $(204,857)$ of publications of all the articles of inclusive design and empowerment published. So, most of the studies are talking about the application of inclusive design and empowerment of community on the newly-developed projects or existing issues rather than the renovation-designed projects. Swift et al., talk about the the value of inclusive design in researching Step-free railway station access in the UK. He conducted an analysis of Senior/Disabled Persons Railcard data from 17 railway stations in Buckinghamshire to demonstrate the potential of Step-free railway station to positively affect the society at large economically, environmentally (Swift et al., 2021). Lu et al., use inclusiveness to thoroughly discuss the design strategy of urban barrier-free facilities integrating regional cultural elements, so as to achieve the effect of integrating barrier-free facilities and the environment with the overall style of the city or region (Lu et al., 2021). Fan talked about the empowerment of community in the protection of traditional villages. He claimed that the public's awareness of participating in planning and decision-making and appeals to the protection and development of traditional villages has become stronger (Fan and Chen, 2021). This paper pays attention to the technique of inclusiveness and empowerment to do the renovation design of the community. 


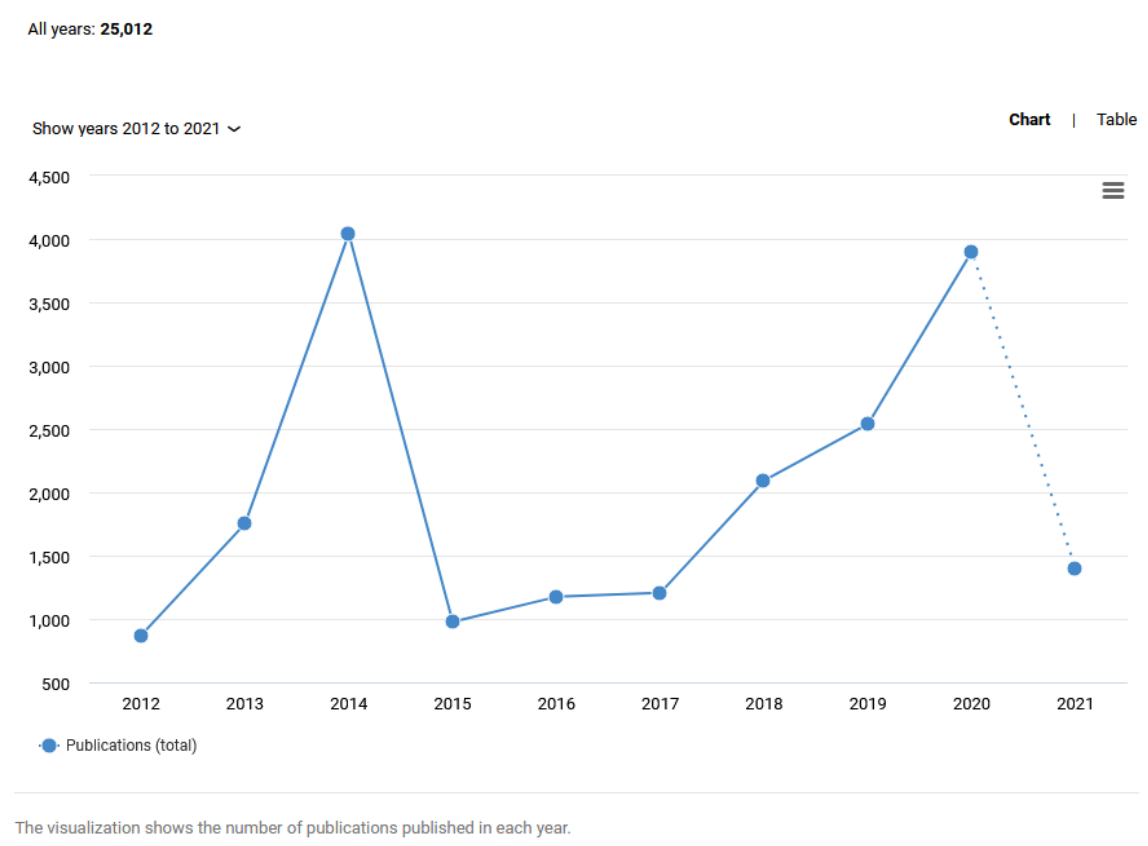

Figure 3. The number of publications of renovation-related articles in English published in each year. Source: https://app.dimensions.ai/discover/publication

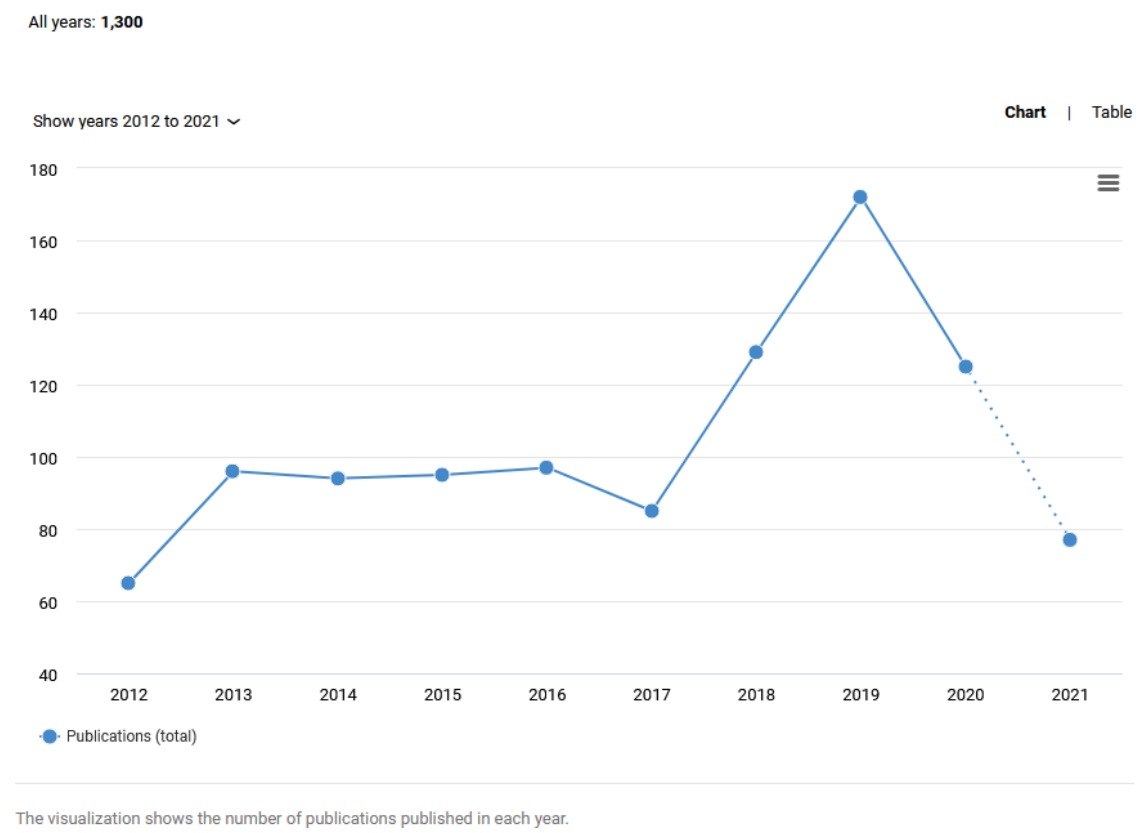

Figure 4. The number of publications of renovation-related articles in Chinese published in each year.

Source: https://app.dimensions.ai/discover/publication

\subsection{The Specific Approaches}

Adding "contextual design" as an extra keyword, Figure 5 and Figure 6 show that the trend of the number of articles related to contextual design published in Chinese and English is Upward. As we can see, contextual design is gaining more and more attention in inclusive design and community empowerment. This paper select two typical articles each used the methods of contextual design and information collecting. Shi analysed the characteristics of users, investigate and summarize the status quo of the inclusive design of Hangzhou Metro lines. The main points of the inclusive design of subway are proposed from the two aspects of horizontal space and vertical space. She also used situational storyboards 
(contextual design) to construct the scene of inclusive groups riding the subway and conduct context analysis to plan and show the ideal subway riding flow and design details for the visually impaired (Shi, 2020). Doran et al., collected the information of the vulnerable group (women, children, and the elderly). They aimed to use the inclusive design of a safe and convenient cycling space suitable for vulnerable groups to meet the different needs of all members of society (Doran et al., 2021). This article summarizes the ten pain points of life scenes of residents which are considered as a contextual design and propose ten optimization strategies to solve the issues.

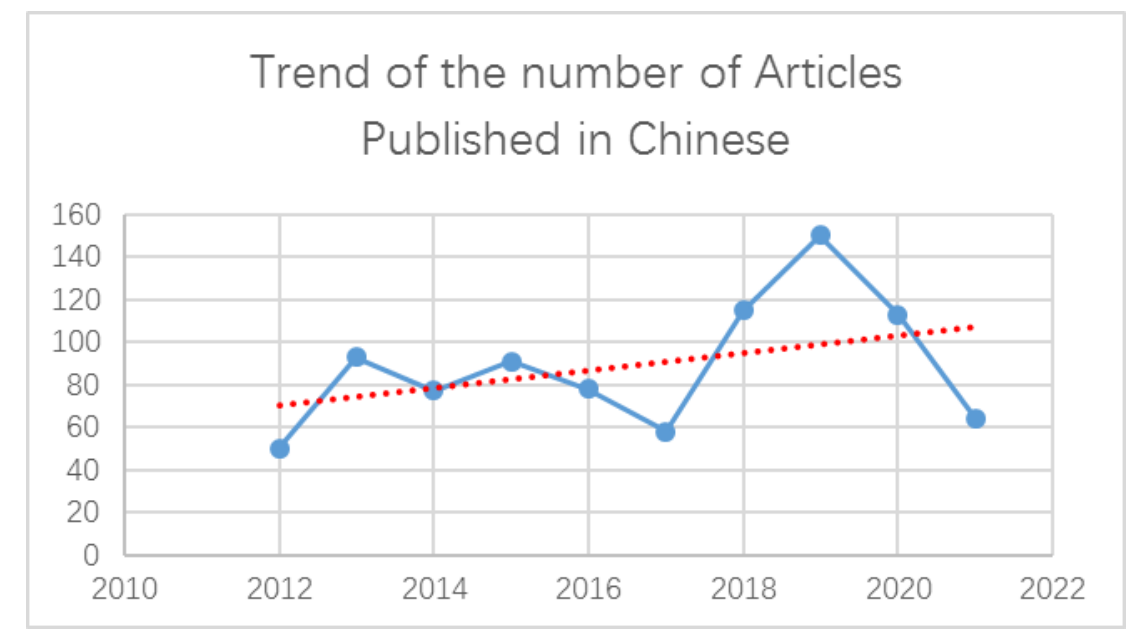

Figure 5. Trend of the number of Contextual-design-related articles in English published in each year.

Source: https://app.dimensions.ai/discover/publication

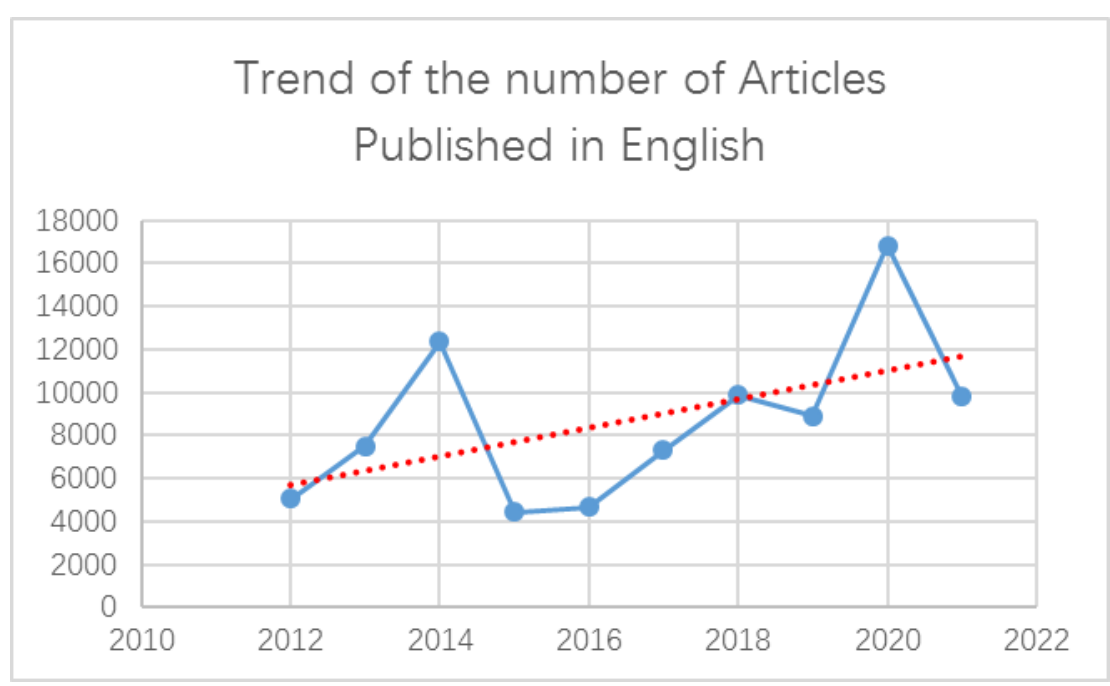

Figure 6. Trend of the number of Contextual-design-related articles in Chinese published in each year.

Source: https://app.dimensions.ai/discover/publication

\section{Methodology}

Besides the common qualitative and quantitative methods of collecting data, the approach the research used is taking the advantage of Inclusive design and empowerment of the community to achieve the "Three Diagrams and One Table" by three steps:

1) Tracking the daily behavior of the residents;

2) Collecting the needs and requirements of the residents; 
3) Simulating the daily-life scene in the community.

The goal of the inclusive design is to reconstruct the community for the requirements of all-aged groups in the community. And the empowerment of the community is an essential tool to understand what the community needs.

\section{Analysis}

\subsection{Site analysis}

The actual case is located in a city in central China. It covers an area of 25.01 hectares, and the built-up area is 200,000 square meters. There are 2,337 families which are about 7,000 residents in the community. The community consists of 13 old neighborhoods, 5 of them have been basically renovated; 6 of them are planned to be renovated in 2021; 2 of them are not renovated at all. Figure 7 shows the general situation of the site.
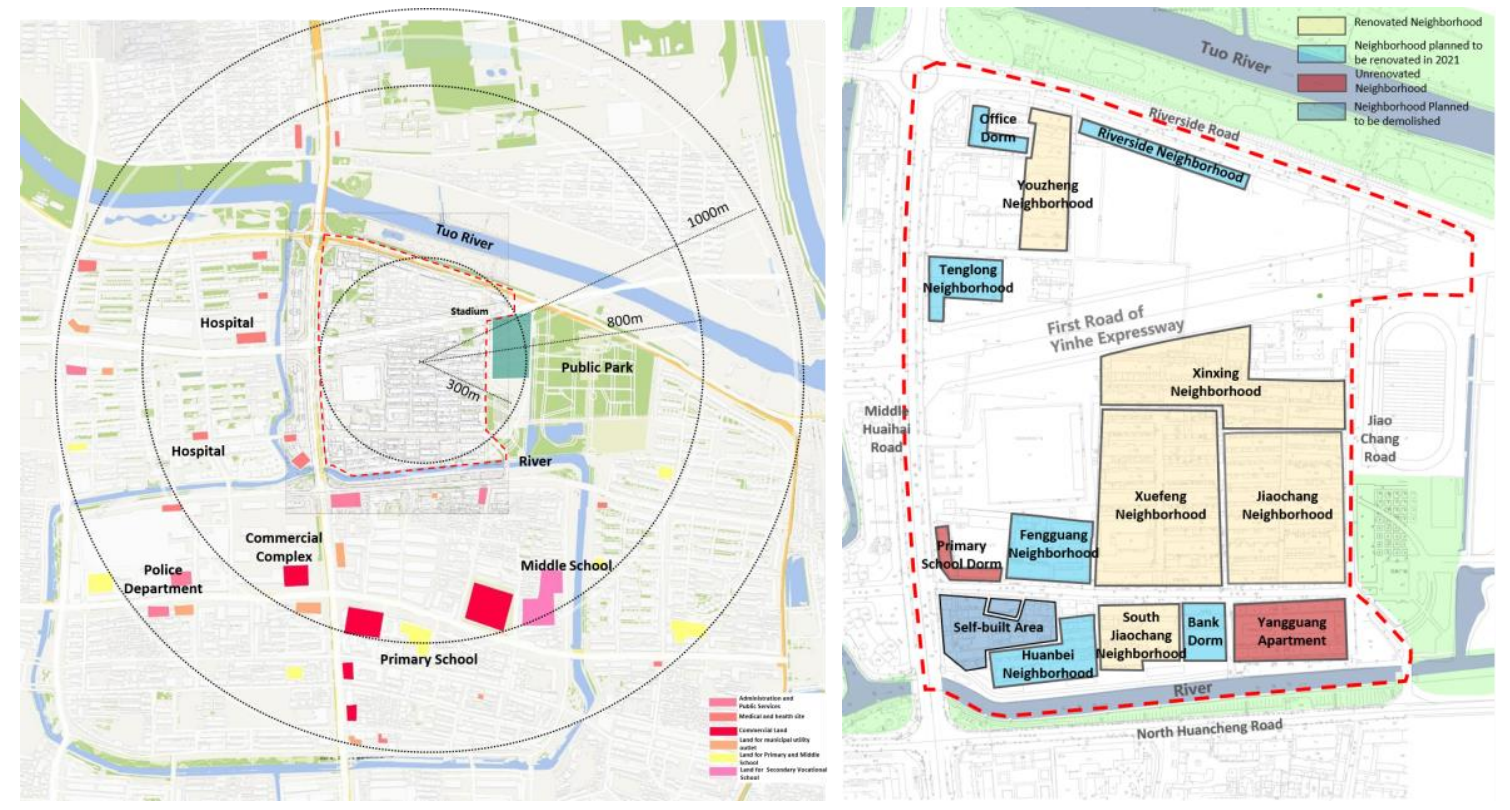

Figure 7. Site Analysis. Source: Baidu Map.

\subsection{Daily behavior of the residents analysis}

First of all, this research divided the residents in the community into four categories: children, the youth, the middle-aged group, and senior citizens.

Second, choosing different times in the morning, midnight, and evening on weekdays and weekends to conduct field research and track the life routes of the four groups of people.

\subsection{Vision Cards analysis}

Third, Conduct public participation surveys in the community like figure 8, make various transformation functional options into "vision cards" for community residents to conduct simulations, and conduct surveys and interviews of residents to summarize their facility requirements and space use difficulties. 

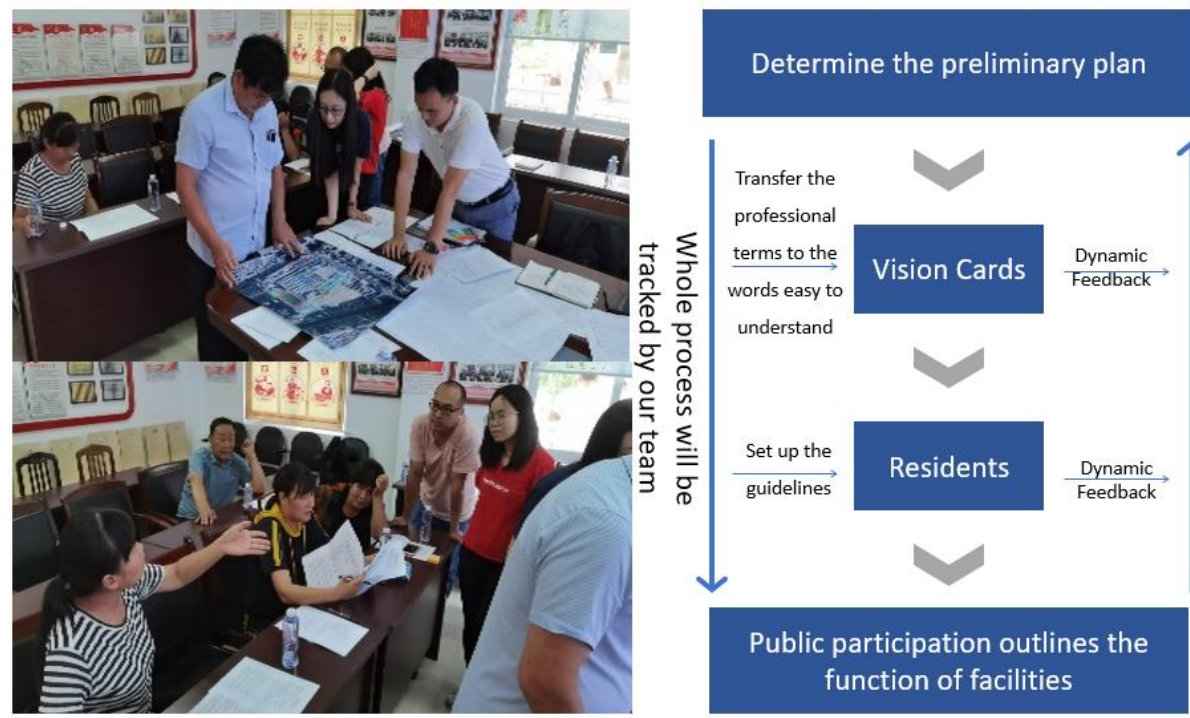

Figure 8. Public participation in the real scene and the technical route of "vision card" participation. Source: self-created.

\subsection{Life scenes and current issues analysis}

At last, Based on the classification needs of the four groups of people, it simulates the ten major scenes of daily life in the community, divided into basic services (dining and entertainment, grocery shopping, parking space, school shuttle, and old-age services), high-quality services (park and recreation, cultural exchanges, Sports, youth nursery, and community management) are analysed to summarize the emergent space problems and the pain points of the current life scene as the conditions and basis for subsequent design. It's showed in Figure 9.

\section{Fundamental Life Scenes}

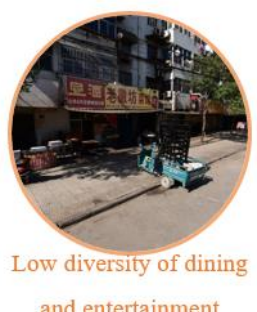

and entertainment

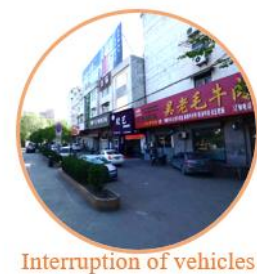

when shopping

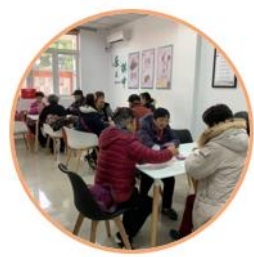

Lack of parking space

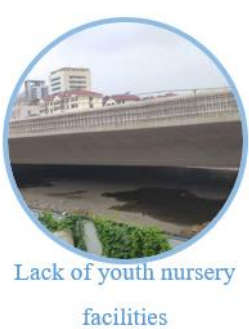

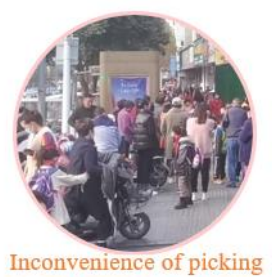

up/dropping off children

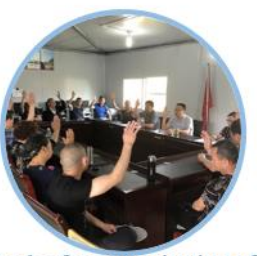

Lack of communication of community management

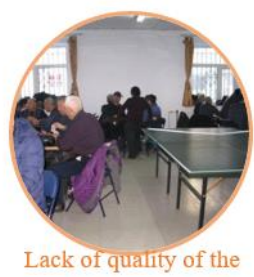

service facilities for the

elderly

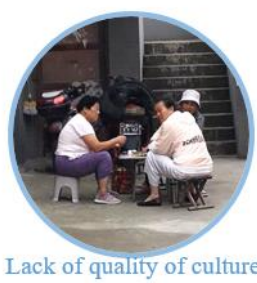

interaction

Figure 9. Summary of ten life scenarios and pain points. Source: self-created. 


\section{Outcomes}

\subsection{The current crowd space behavior analysis diagram}

The daily life of children in the community was simply between preschool and home except for a few shopping and eating activities on the road to school/home due to the lack of internal activity areas in the existing community, the isolation of the southern riverside landscape belt, and the mixed-using lane of people and vehicles affects the safety and other reasons.

The research showed that there was not much youth in the community, and most of them moved to a higher-quality community for living. A small number of youth groups who still stayed in the community only use the community as a place to sleep due to insufficient recreational facilities.

The research also claimed that the middle-aged group always worked outside of the community and had a lot of interactions with the group of children. The daily life of them was involving with grocery shopping and household working.

At last, the results demonstrate that the senior citizen played a huge role in the community. The number of elderly people accounted for a large part of the community, usually in the southern district, northern riverside landscape belts, and the corner spaces in the community assembled to organize community activities. The results of the residents' behaviors of the four-aged group could be summarized as "The Current Crowd Space Behavior Analysis Diagram" by Figure 10.

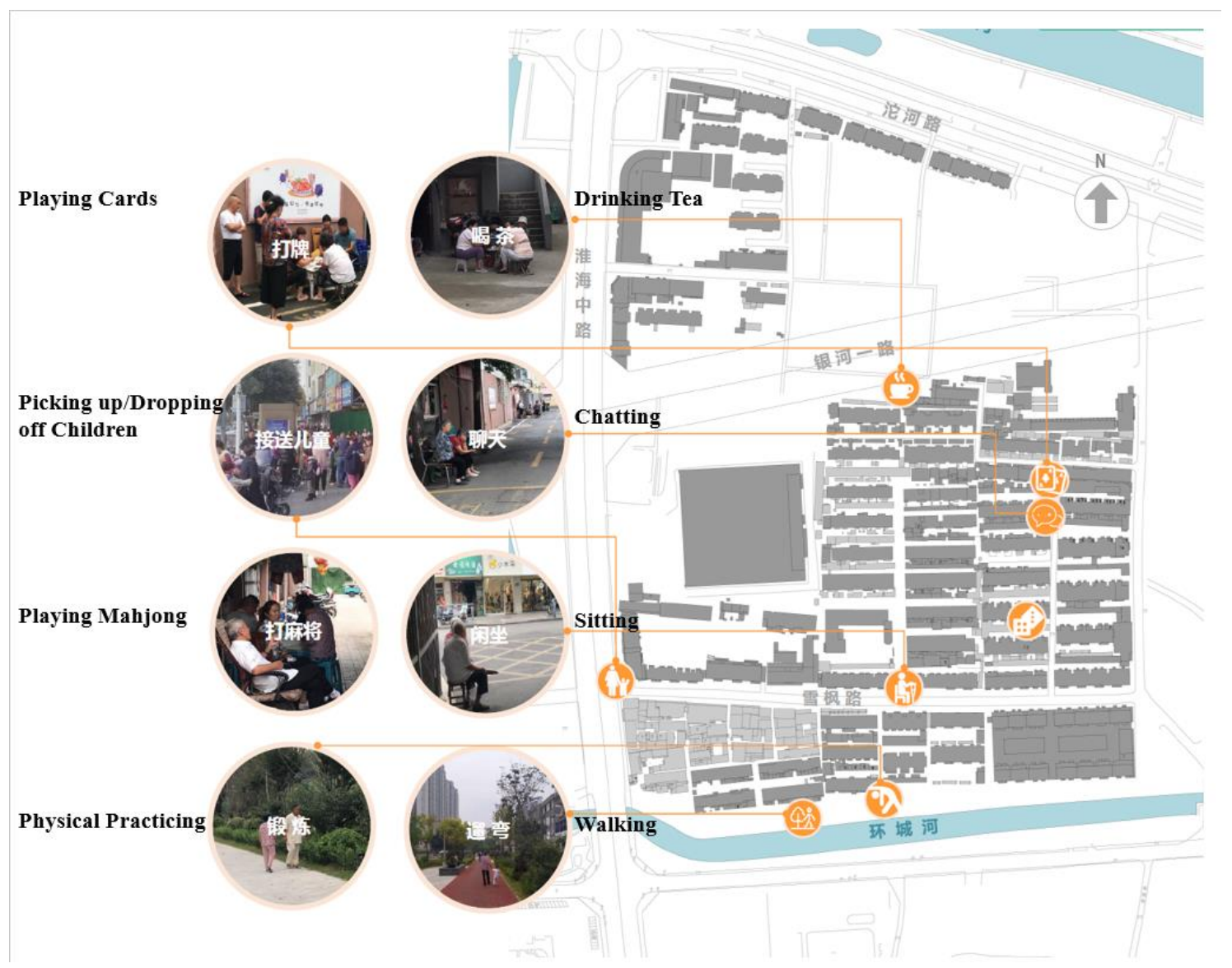

Figure 10. The current crowd space behavior analysis diagram. Source: self-created. 


\subsection{Residents demand statistical information table and Crowd space facility demand mark} diagram.

The community residents had various expectations for future functions of the community, including retail business, leisure and recreation, nursery facilities, medical care, sports, etc., according to the vision cards and the further analysis combined with the field research, it is found that different groups of people had different requirements for the community facilities:

- Children: some safe playgrounds and the food retails no longer occupy the roads in the community

- Youth: commercial and entertainment area and physical practicing facilities

- Middle-Aged group: supermarket without the interruption of vehicles, parking lot, and a safe space/road for picking up/dropping off children

- Senior citizens: accessibility facilities, accessible physical practising facilities, safe space for assembling activities, and continuous public space for walking

The findings of vision cards, questionnaires, and interviews were generated into a "Crowd Space Facility Demand Marking Map" and a "Residents Demand Statistical Information Table" demonstrated in Figure 11.

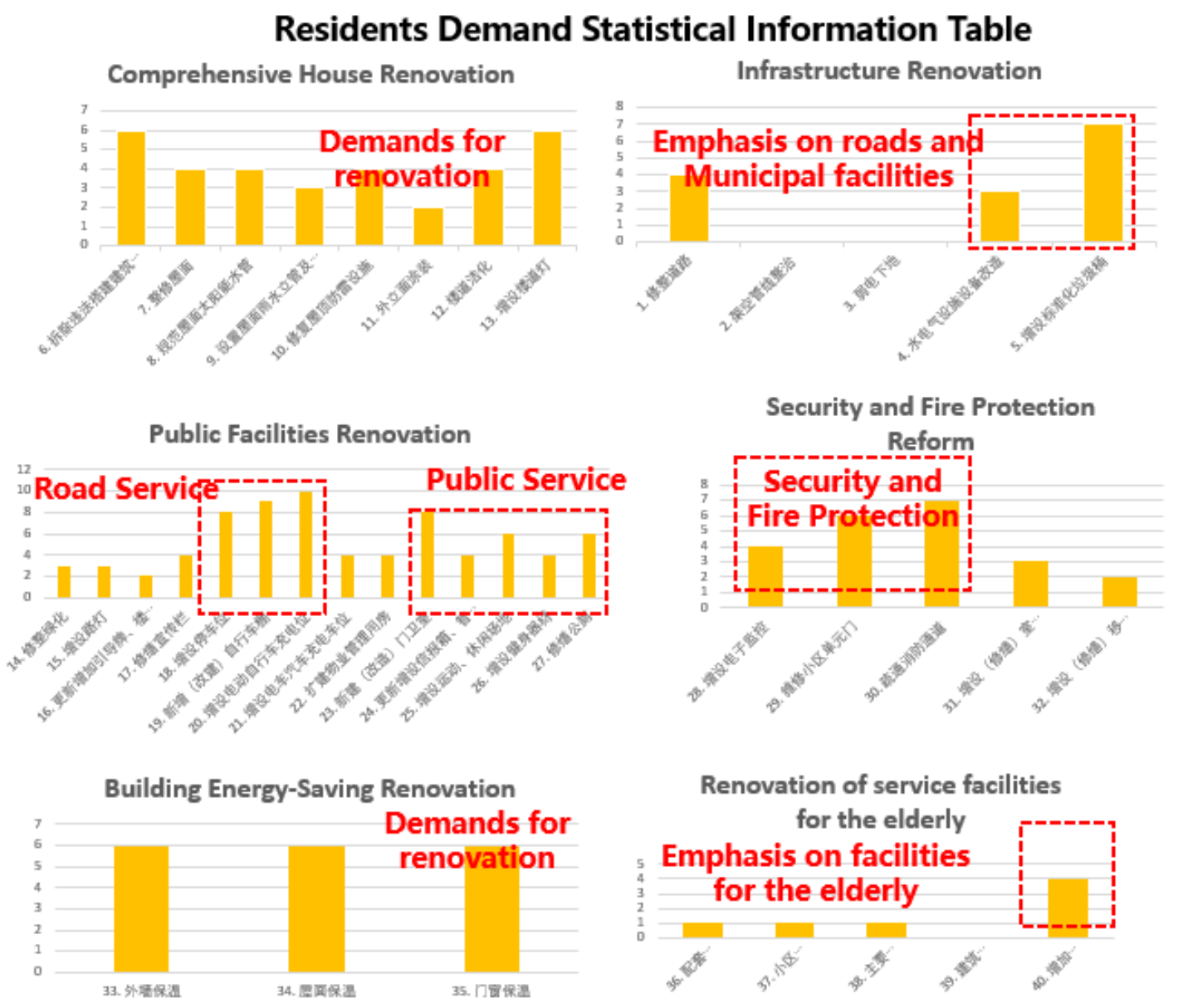

Figure 11. Residents demand satirical information table and Crowd space facility demand mark diagram. Source: self-created. 


\subsection{Current resident living scene simulation diagram（现状居民生活场景模拟图）}

According to the field survey of the life scenes of residents, the results were organized and summarized in to a The "Current resident living scene simulation diagram" showed by Figure 12.

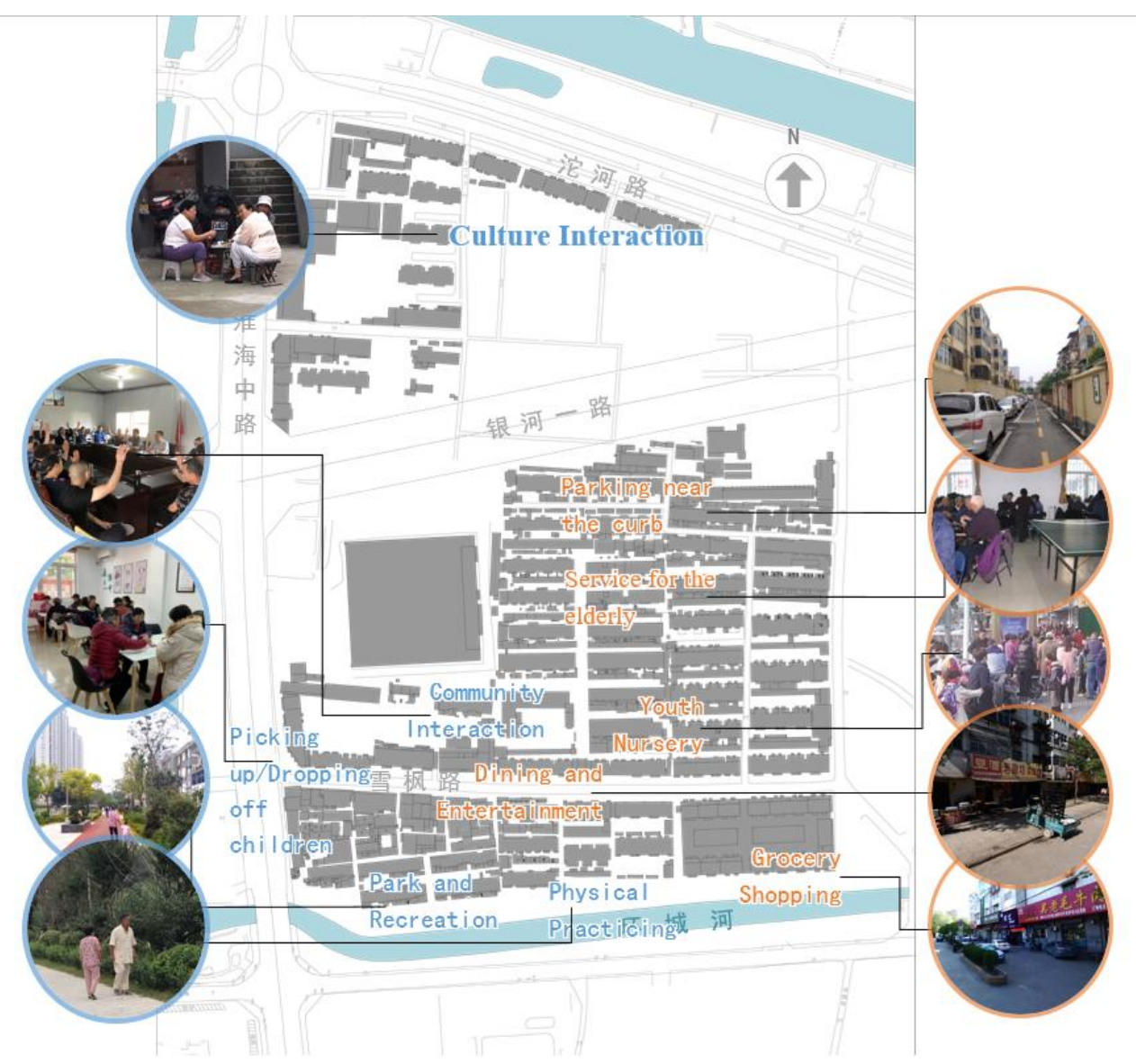

Figure 12. Current resident living scene simulation diagram. Source: self-created.

\section{Implementation}

\subsection{Four types of supporting services}

Based on the "Completed residential community construction standards (for trial implementation)"(Design, 2018), "Shanghai 15-minute community life circle planning research and practice"(Administration et al., 2017), related articles, actual cases, and the characteristics of the needs of the various age-groups, there are four types of facilities need to be installed in the community.

First, a series of centralized facilities (Fig. 13) which able to stimulate the vitality of the community to meet the needs of grocery shopping and social interactions (community hall, supermarket) for the middle-aged group and the elderly, cultural entertainment and physical practising (court of basketball) for the Youth.

Second, a group of pocket convenience points (Fig. 14) has the capacity to make the community more convenient for the residents to live in. It could be reached by improving the fundamental needs for the daily life of the residents and constructing mobile service facilities, such as fresh food containers, mobile restrooms, temporary delivery storage, and vending machines. 
Third, the smart interaction center and the smart interaction screens (Fig. 15) are responsible for responding to the resident's needs for the upgrade of community management and service. The community was divided and isolated to a few blocks by a series of intelligent security installations, for example, face ID, fingerprint recognition, application on cell phones and monitors. The smart interaction center is an integrated platform that has a large screen and includes the following information of the commercial area, property management, early alert service for natural hazards and pandemics. They will be implemented on the location that has a large flow of traffic to do the advertising.

Fourth, the special quality points (Fig. 16) addressed the problem of lacking high quality of open space in the community. They were designed as the landscaping space under the expressway, the inner resting space in the housing estate, the riverside green space, and the open space on the building roof.

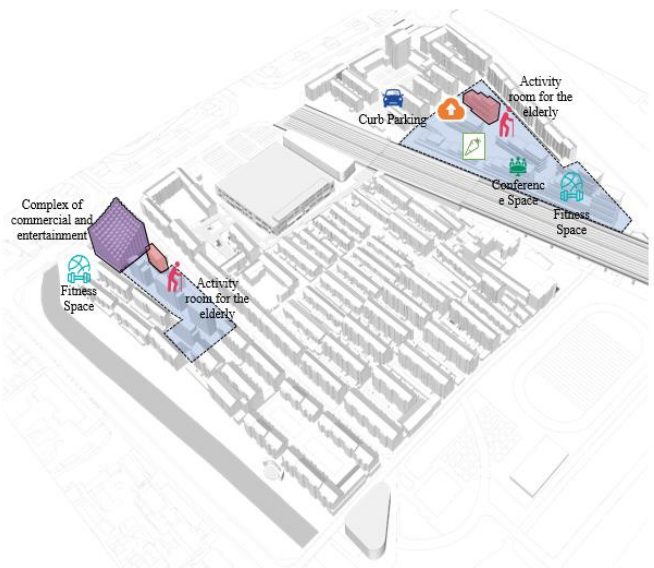

Figure 13. Spatial Layout of centralized facilities. point.

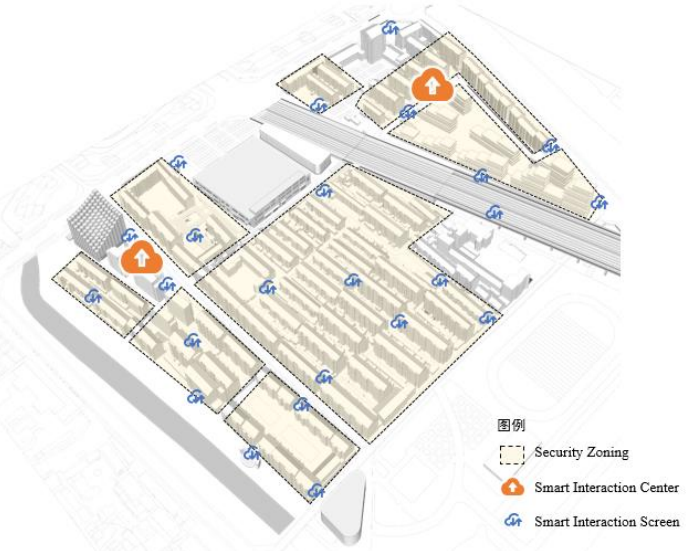

Figure 15. Spatial layout of smart interaction points.

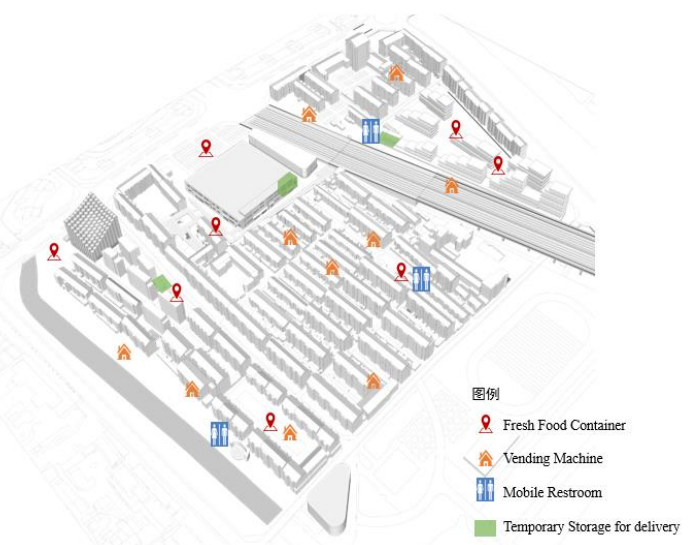

Figure 14. Spatial layout of pocket convenience

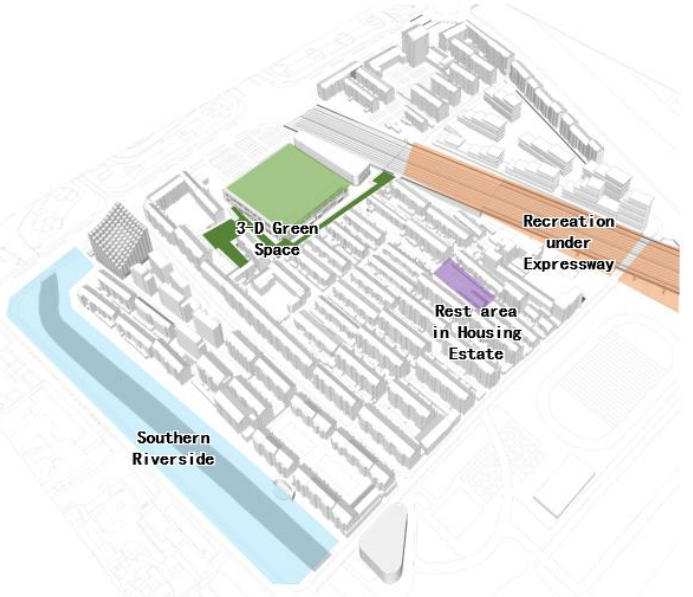

Figure 16. Spatial layout of high quality point.

Source: self-created.

\subsection{Two types of life scenes}

According to the "Three Diagrams and One Table", the project wants to promote both two types of life scenes, the fundamental service, and high-quality service for the residents.

The promotion of life scene of fundamental service: 1) the current dining and entertainment service is only supplied by the supermarket. It will be altered by updating the ground floor for retails to a 
commercial street and adding a complex of commercial and entertainment; 2) redeveloping the supermarket and installing several pickup points like the pickup towers of Walmart to improve the scene of food shopping; 3 ) cars are no longer to park near a curb or the small parking lot near the supermarket. Underground parking space and the multistorey car park will be built to fulfill the parking needs; 4) the pick-up/drop-off scene will be transferred to the front yard in the community hall to not only reduce the congestion but also avoid the danger of traffic; 5) upgrading the community daycare center for the senior citizen in the community. It refers to facilities that provide daycare services such as meal supply, personal care, health rehabilitation, leisure, and entertainment for the semi-disabled elderly who cannot take care of themselves completely in the community and need some care in daily life. In addition, a smart health network is set up in the northern part of the community to track health data to ensure the safety of the elderly at any time. The whole implementation is shown in Figure 17.
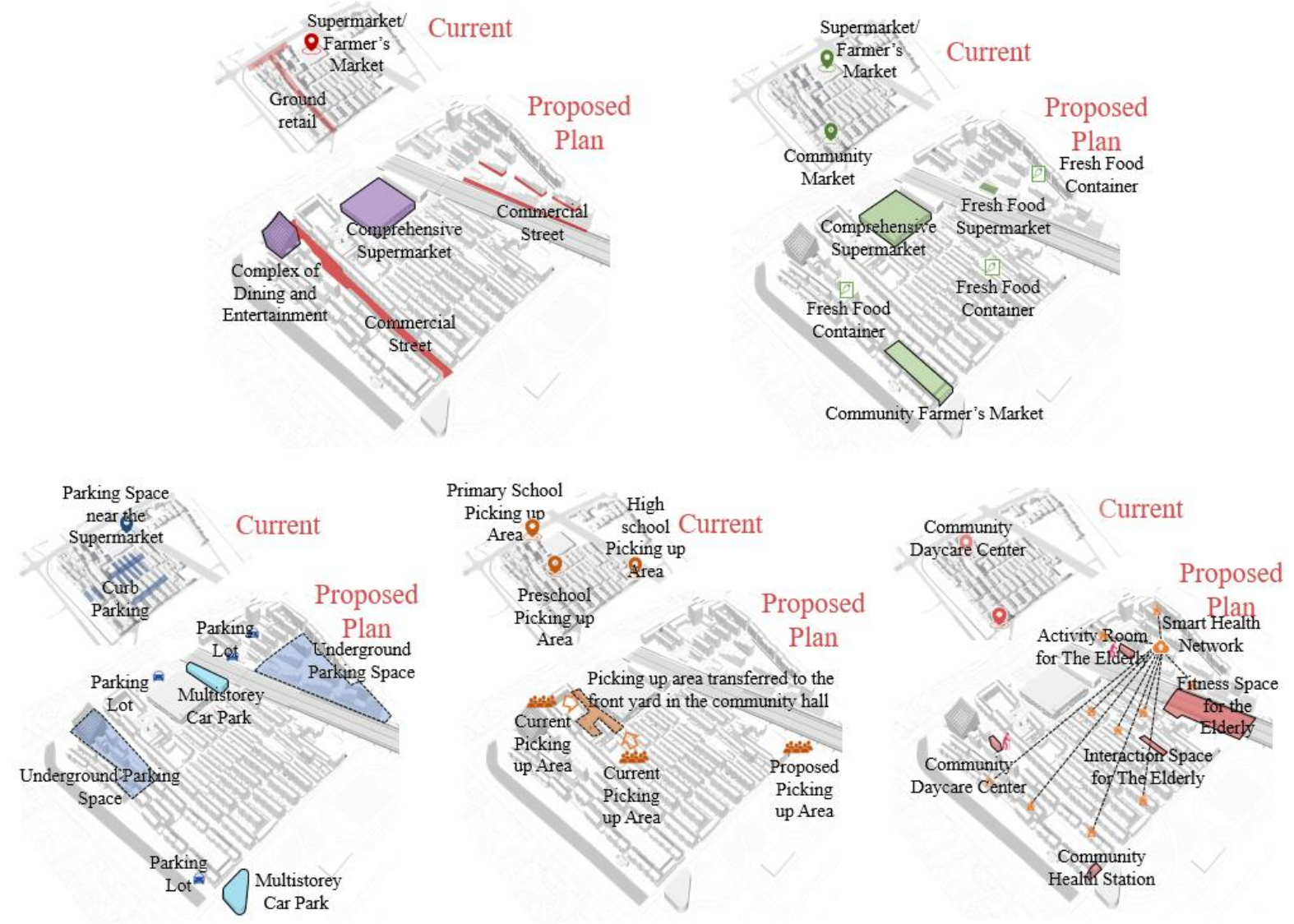

Figure 17. Layout of facilities to improve basic service life scenes. Source: self-created.

The promotion of high-quality service: 1) there are few park and rest areas in the community. By making use of the space under the bridge and the unused vacant land, some green plazas will be added to the community. The roof of the farmer's market was also planned as a roof garden. A pedestrian walking path connects these amusement venues to meet the needs of interpersonal communication and relaxation, and activate the vitality of the community; 2) the community lacks cultural activities. Although a book reading room is set up, few people use it. It is planned to build the community into a cultural community. The cultural activity center, community residences, 3-D green gardens, and an outdoor small theater will be used as the main venues for the restoration of cultural activities. Small venues are evenly distributed in the community to enrich the activity scenes; 3 ) combined with the construction of community squares, street green spaces, and public spaces, fitness venues will be spread all over the community; 4) youth nursery, adding an art activity center, a youth activity center, and three childcare centers to serve residents and surrounding people; 5) The community will cooperate with Tencent and 
other advanced platforms to seamlessly connect with wearable devices to build connection among different housing estates. The community adds three pickup centers and multiple community communication centers. The whole implementation is shown in Figure 18.
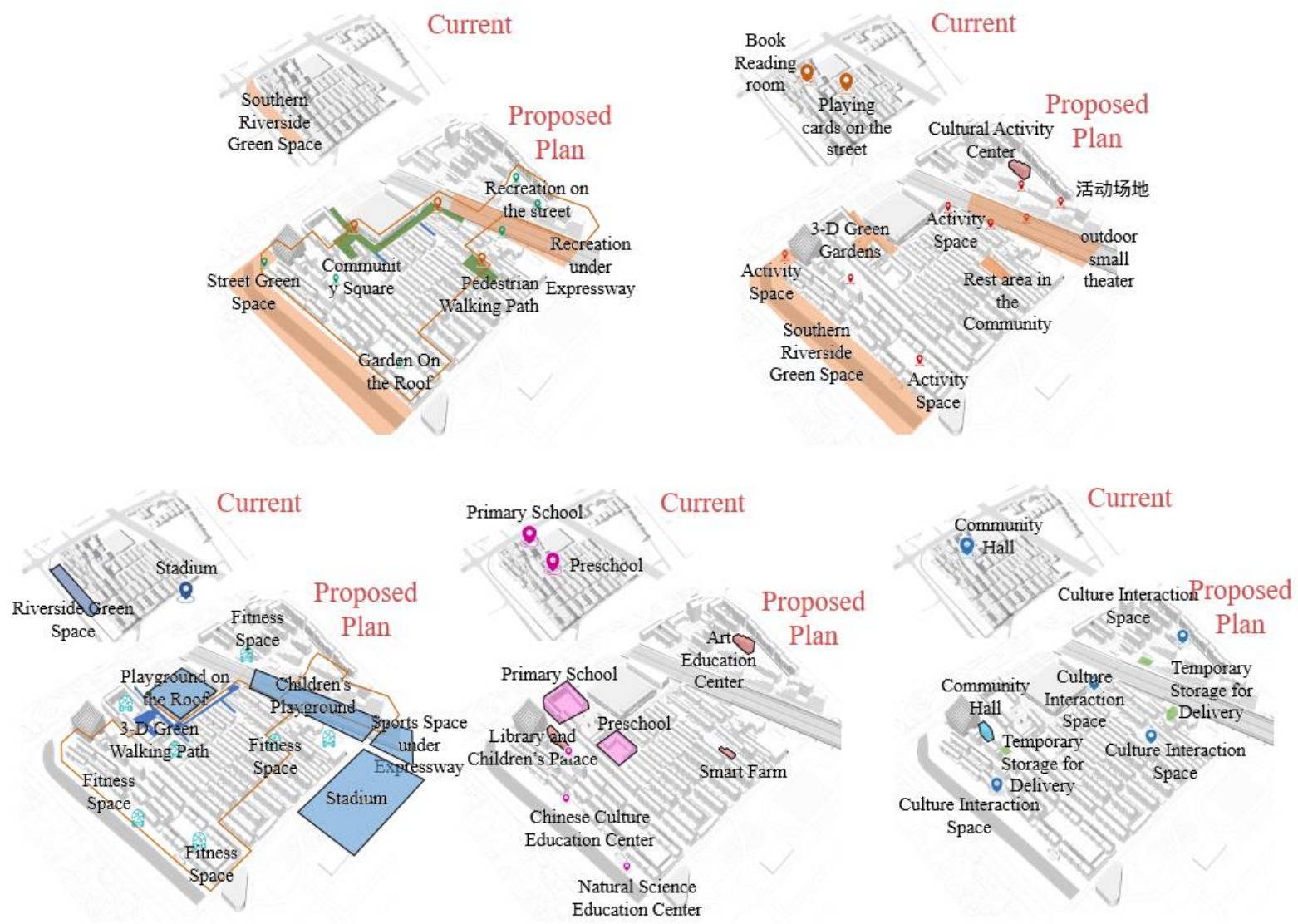

Figure 18. Layout of facilities to improve quality of life scenes. Source: self-created.

\section{Conclusion and Prospect}

This article takes an old community in China as an example. Through inclusive design and community empowerment such as questionnaire adjustments, panel interviews, demand cards, scene simulations, etc., this article summarizes the current situation of the case and the space dominating the daily behavior and activity space of the crowd and draws charts. Form the "three-diagram and one-table" work model and conduct crowd portrayal and demand simulations, arrange four types of supporting facilities and shape ten major life scenarios, hoping to enrich the empirical experience of inclusive design and community empowerment and plan and design for the scale below the mesoscale Provide reference for renovation and renewal projects.

There are three limitations: 1 ) since the actual project was in progress when this article was formed, after the proposal was generated, the collection of feedback on the simulation of the live scene and the design proposal participated by the residents was not sufficient, and the accuracy of the scene simulation needs to be improved; 2 ) There are few actual cases of inclusive design and community empowerment in China, and the project area is relatively concentrated. It is necessary to further study whether it can be applied to communities with different characteristics in different regions; 3 ) the method of obtaining information is still based on traditional field surveys and manual sorting and analysis. It's hard to timely conduct indepth monitoring and evaluation of the results of scene simulation with more updated data. 
According to the Location Based System (LBS) and street view and face recognition technique, the threshold for obtaining community activity data is constantly lowering. Applying the data obtained using new technology to the design strategy of this article can greatly increase the diversity of data sources and better verify the results of population division and demand matching. In future practice, more subcategories, such as "owner-renter", gender, occupation, etc., can be divided based on the characteristics of the community on the basis of age groups, so as to carry out more precise population portrait and characterization. The design process can pay more attention to the impact of online activities on offline living spaces, open up the boundary between the Internet and reality in order to improve the comprehensiveness and accuracy of the scene description.

\section{References}

ADMINISTRATION, S. M. P. A. L. R., CENTER, S. P. R. \& INSTITUTE, S. U. P. A. D. 2017. Shanghai 15-minute community life circle planning research and practice, Shanghai People's Publishing House.

DE WEGER, E., VAN VOOREN, N., LUIJKX, K. G., BAAN, C. A. \& DREWES, H. W. 2018. Achieving successful community engagement: a rapid realist review. BMC Health Services Research, 18, 285.

DESIGN, C. A. O. U. P. 2018. Completed residential community construction standards (for trial implementation). In: DEVELOPMENT, M. O. H. A. U.-R. (ed.). Beijing: China Architecture Publishing \& Media Co., Ltd.

DORAN, A., EL-GENEIDY, A. \& MANAUGH, K. 2021. The pursuit of cycling equity: A review of Canadian transport plans. Journal of Transport Geography, 90, 102927.

FAN, S. \& CHEN, X. 2021. Research on the Protection and Development of Traditional Villages Based on the Perspective of Community Construction. Development of Small Cities \& Towns, 39, 50-55.

H, K. N. \& W, R. 2021. Evaluating human-centered design methods as an approach for inclusive green design: Case study Kampung Kota Surakarta. IOP Conference Series: Earth and Environmental Science, 780.

HüBSCHER, M. \& RINGEL, J. 2021. Opaque Urban Planning. The Megaproject Santa Cruz Verde 2030 Seen from the Local Perspective (Tenerife, Spain). Urban Science, 5, 32.

LU, Q., ZHANG, N., ZOU, S. \& WANG, J. 2021. Discussion on the Urban Barrier-Free Design Integrating Regional Cultural Elements. Wetern Leather, 43, 69-70.

PRC, T. S. C. O. 2020. Guiding Opinions of the General Office of the State Council on Comprehensively Promoting the Reconstruction of Old Communities in Urban Areas. The Bulletin of the State Council of the People's Republic of China 11-15.

SHI, W. 2020. Inclusive design and optimization strategy of Hangzhou Metro. Urban Transportation of China, 18, 75-83+17.

SWIFT, A., CHENG, L., LOO, B. P. Y., CAO, M. \& WITLOX, F. 2021. Step-free railway station access in the UK: the value of inclusive design. European Transport Research Review, 13, 45.

ZHU, X., ZHOU, Y., YAN, Z. \& JING, H. 2019. How the old community involving hundreds of millions of residents should be changed? Xinhua Agency. 07/25 Ed. 